\title{
LUT
}

University

\section{Purification efficiency of natural freeze crystallization for urban wastewaters}

\author{
John Miia, Häkkinen Antti, Louhi-Kultanen Marjatta
}

This is a Final draft version of a publication

published by Elsevier

in Cold Regions Science and Technology

DOI: $\quad 10.1016 /$ j.coldregions.2019.102953

Copyright of the original publication: ( 2019 Elsevier

Please cite the publication as follows:

John, M., Häkkinen, A., Louhi-Kultanen, M. (2019). Purification efficiency of natural freeze crystallization for urban wastewaters. Cold Regions Science and Technology, vol. 170. DOI: 10.1016/j.coldregions.2019.102953

This is a parallel published version of an original publication. This version can differ from the original published article. 


\title{
Purification efficiency of natural freeze crystallization for urban wastewaters
}

\author{
Miia John ${ }^{\mathrm{a}, *}$, Antti Häkkinen ${ }^{\mathrm{a}}$, Marjatta Louhi-Kultanen ${ }^{\mathrm{b}}$ \\ ${ }^{a}$ Department of Separation and Purification Technology, LUT School of Engineering Science, LUT University, \\ P. O. Box 20, Fl-53850 Lappeenranta, Finland \\ ${ }^{b}$ Department of Chemical and Metallurgical Engineering, School of Chemical Engineering, Aalto University, \\ P.O. Box 16100, Fl-00076 Aalto, Finland
}

\section{Abstract}

Human population growth and urbanization are aggravating water quality problems in many regions, and wastewater volumes and quantities of pollutants are increasing due to greater industrial and urban activity. Thus, it is necessary to find efficient, sustainable and simple methods to separate miscellaneous impurities from wastewaters. One potential separation methods is freeze crystallization, because of its non-selective nature. However, previous research investigating freeze separation using real wastewaters has been rather marginal.

This study examines natural freeze crystallization in purification of urban origin wastewaters, that is, municipal wastewater and landfill leachate of various organic and inorganic matter concentration. The effect of different freezing conditions on ice growth and separation efficiency in terms of ice impurity relative to initial solution impurity was investigated with a laboratory scale winter simulator. The results showed air flow velocity to have an almost as significant an influence on ice mass growth as air temperature. Although separation efficiencies decreased linearly with increased ice growth rates, no clear correlation was found between the impurity concentration of the wastewater and the ice mass growth rate. This finding notwithstanding, the separation efficiency of freeze crystallization of concentrated wastewater (landfill leachate) was noted to decrease more clearly with increased ice growth rate. Purification efficiencies of $95 \%$ to nearly $100 \%$, determined by indicators such as chemical oxygen demand (COD), were achieved in 
treatment of municipal wastewater when using low ice growth rates. These findings indicate that the approach can meet future legislative requirements for treatment plants and that further research of the utilization of freezing techniques for wastewater purification is warranted.

Keywords: Freezing point depression; Ice purity; Impurity removal; Natural freezing; Wastewater treatment

\section{Introduction}

Increased environmental awareness among urban populations means that there is now little need to restate arguments articulating the importance of water saving and water protection activities. To date, conventional wastewater treatment plants are designed to remove organic matter and nutrients from wastewaters for environmental protection and to minimize pathogenic microorganism populations in effluent for sanitary reasons. However, concerns have recently been raised over the adequacy of the wastewater treatment methods currently used and the quality and characteristics of the effluent discharged (Prasse et al., 2015).

Constantly improving living standards among urban populations together with wastewater treatment plants with very large population equivalent have resulted in increased quantities of socalled emerging contaminants in discharged effluents. Enrichment of effluents with micropollutants like pharmaceuticals, antibiotics, synthetic sweeteners and personal care products used in everyday life affect adversely the aquatic environment, flora and fauna, and, ultimately, human health (Rodriguez-Narvaez et al., 2017). Improved knowledge and a changed socioeconomic context thus mean that new or complementary methods are needed for advanced wastewater treatment to ensure adequate removal of organic and inorganic matter, nutrients and micropollutants. In addition to being effective, the capital, operating and maintenance costs of such innovative wastewater treatment technologies must remain economically acceptable.

Freeze crystallization is one potential alternative wastewater purification method, as ice possesses natural high intolerance towards impurities (Bogdan and Molina, 2017). When impure 
water freezes, the water molecules tend to crystallize, i.e. arrange into as pure ice as possible, while impurities are disposed to the remaining liquid water. High separation efficiency of impurities is therefore achievable, provided impurities are not entrapped as inclusions inside the bulk ice. Freeze crystallization is recognized as an energy-efficient and simple water treatment process that needs no chemicals, and it can be assumed that operating costs will be modest and total environmental impact relatively minor (Yin et al., 2017). In the freeze separation process, nutrients in the wastewater are concentrated in the residual liquid in their initial form, for the most part, because no significant biological or chemical reactions occur. As a result, efficient and sustainable recovery of nutrients is possible.

Ice and the freezing process have been studied for decades in many different fields of engineering science and there are many applications where freezing is used to separate water from liquid mixtures and solutions. For instance, freeze concentration has been used in the food industry to produce high quality fruit juice and coffee extracts. Similarly, freeze separation has been used as a desalination process in fresh water production, although mainly on a laboratory scale (Chang et al., 2016; Williams et al., 2015). Eutectic freeze crystallization (EFC), a special form of melt crystallization, can be considered a fairly sophisticated application for water and salt separation because at the eutectic point, ice and salt can be crystallized simultaneously from the electrolyte solution. In EFC studies, attention has been directed to recovery of the salt formed as well as the water treatment itself (Hasan et al., 2017). In recent years, freeze crystallization research has principally focused on the development of experimental or pilot-scale equipment and devices for separation of a specific compound, e.g. sodium carbonate or sodium sulphate from specific industrial wastewater streams or brine (Williams et al., 2015; Randall and Nathoo, 2015). For example, Randall et al. (2014) used wastewater from a textile plant in investigation of a cascading EFC procedure in a jacketed crystallizer. In their study, $98 \%$ ice purity and $30 \%$ yield of sodium sulphate were achieved. Ice produced by suspension freeze crystallization from brines has also 
been shown to be very pure. For instance, van der Ham et al. (2004) obtained impurity concentrations in ice below $100 \mathrm{ppm}$ of copper in an EFC-based cooled disk column crystallizer with an initial copper sulphate solution concentration of $0.145 \mathrm{~kg}_{\text {salt }} / \mathrm{kg}_{\text {solution. }}$. Utilization of more efficient washing of ice enabled levels of $5 \mathrm{ppm}$ or less to be achieved.

Freeze purification (or separation) studies have been undertaken mostly using model or synthetic wastewater and few studies have used real wastewaters. Work reporting the purification efficiency of total organic or inorganic matter when using urban origin wastewaters, which are complex multicomponent aqueous solutions, is even more limited. In the area of industrial wastewaters, Gao et al. (1999) studied ice nucleation by spray droplets with a pulp mill effluent, piggery wastewater and oil sands tailings pond water. They continued their spray freezing studies in field conditions with the same industrial waters and achieved $\geq 60 \%$ impurity reduction efficiencies for chemical oxygen demand (COD), electrical conductivity and color. Different efficiencies were found for organic and inorganic matter (Gao et al., 2004). A few years later, the same research group compared laboratory-scale spray and unidirectional downward freezing techniques with oil refinery and pulp mill effluents. Layer freezing with mixing of the liquid resulted in the greatest organic contaminants reduction, $90-96 \%$ reduction (based on COD and total organic carbon (TOC) analysis). Without mixing, the efficiency was much lower; it was at the same level as spray freezing (Gao et al., 2009).

The separation efficiency of freeze concentration with a rotating evaporator for soluble pollution in urban wastewater, food factory effluents and cutting oil wastewater was studied by Lorain et al. (2001). The study attained close to $100 \%$ separation efficiency for TOC (i.e. organic matter). Similar very high purity of the ice layer (measured by COD) was found also by Shirai et al. (1998) in layer freezing studies with food industry (dairy and rice cracker) wastewaters. The spray freezing research carried out in field conditions by Bigger et al. (2005) with mining tailings lake water achieved $87-99 \%$ removal of mostly inorganic matter when measured with electric 
100

101

102

103

104

105

106

107

108

109

110

111

112

113

114

115

116

117

118

119

120

121

122

123

conductivity. Their work also analyzed removal of some ions, elements and toxins such as arsenic and cyanide. It should be noted, however, that mining waters can also contain significant amounts of organic matter in addition to heavy metals, as detected in our previous study of natural freezing in mine wastewater basins (John et al., 2018).

Some freezing studies have investigated compounds that are now classified as micropollutants. Gao and Shao (2009) studied two commonly used pharmaceuticals, namely the anti-inflammatory drug ibuprofen and the antibiotic sulfamethoxazole. Their work used model solutions and analyzed TOC as a gross parameter. They found that pharmaceuticals content reduced by $84-$ $92 \%$ in single-stage freeze concentration and about $99 \%$ in a two-stage ice layer freezing process. Yin et al. (2017) studied a Grignard reagent wastewater from a pharmaceutical intermediates company that contained the organic solvent tetrahydrofuran. COD removal of $>90 \%$ was found when using layer freezing and suspension crystallization. Feng et al. (2018) proposed a freezing concept for use with oil recovery from waste cutting fluids. 90\% COD removal efficiency was obtained with suspension crystallization.

Previous freezing studies with real wastewaters have implemented freezing techniques at temperatures varying from $-2{ }^{\circ} \mathrm{C}$ in the laboratory to $-33^{\circ} \mathrm{C}$ in field conditions. The studies give only little information about the ice production rate at specific conditions, and appraisal of the total potential efficacy of the freeze separation process is hence difficult, even though the separation efficiency for some impurities was shown to be high and sometimes close to $100 \%$.

This study investigates ice layer growth and purification efficiency of natural air-cooled freezing of urban wastewaters originating from a municipal wastewater treatment plant and solid waste landfill. The effect of freezing conditions (i.e. air flow velocity and temperature) on ice mass growth and separation efficiency was examined under controlled conditions using winter simulation apparatus. The freezing point depression temperatures of the studied wastewaters were 
124 experimentally determined to initialize the thermodynamic actions and to ensure the comparability

125 of the freezing temperatures of the different wastewaters.

\section{Materials and methods}

127

128

129

130

131

132

133

134

135

136

137

138

139

140

141

142 from 80 to $120 \mathrm{~m}^{3}$.

143 Urban wastewater is a very complex mixture of compounds and pollutants that have accumulated 144 in water. The quality and composition of the wastewater also varies periodically due to fluctuating 145 flow rates caused by domestic water use and precipitation. Infiltration water of landfills is formed 146

\subsection{Wastewaters}

In this study, real wastewaters from a municipal wastewater treatment plant and leachate from a solid waste landfill were used as the feed water for the freezing experiments. Both sites, the Toikansuo wastewater treatment plant and the Kukkuroinmäki landfill, are situated in the city of Lappeenranta in southeastern Finland. The municipal wastewater contains mainly domestic wastewater, with some industrial wastewater, from a residential population of 60000 and average daily wastewater volume is $16000 \mathrm{~m}^{3}$. The wastewater for the tests was collected from the open water stream after primary clarification and before the water flows to the biological (activated sludge) reactor tank. The wastewater is chemically pretreated in a primary sedimentation basin with calcium hydroxide $\mathrm{Ca}(\mathrm{OH})_{2}$ and ferric sulphate $\mathrm{Fe}_{2}\left(\mathrm{SO}_{4}\right)_{3}$ (feeds $\sim 150 \mathrm{~g}$ per m $\mathrm{m}^{3}$ wastewater) for $\mathrm{pH}$ adjustment and suspended solids reduction, respectively. Fully processed effluent from the same plant was also collected to be able to test very dilute wastewater. The landfill is situated next to the regional solid waste management center serving municipalities in the area. The landfill leachate water was collected from the inspection and pumping well that captures infiltration water from the normal (non-hazardous) solid waste fill. Total daily leachate volume of the landfill varies by precipitation and melting snow and contains residues from the waste material as well as solid filling material. Both sites, the wastewater treatment plant and the landfill, have a statutory 
148 obligation to monitor water quality frequently. Average analyzed compositions of the studied 149 wastewaters are presented in Table 1. Although the landfill leachate contains almost twice the 150 amount of organic matter found in the municipal pretreated wastewater, the biological activity of 151 the municipal pretreated wastewater can be expected to be higher due to its larger microbial 152 population. The measured conductivity of the leachate is high, indicating a high concentration of 153 ionic inorganic matter. The landfill leachate most likely contains small particles like microplastics 154 and fibers, as bigger pieces were visible in the raw water samples.

155 Table 1. Composition of tested wastewaters.

\begin{tabular}{|c|c|c|c|c|c|c|}
\hline Wastewater & $\begin{array}{c}\text { COD } \\
\left(\mathrm{mg} \mathrm{L}^{-1}\right)\end{array}$ & $\begin{array}{l}\text { Color } \\
\text { (PtCo) }\end{array}$ & $\begin{array}{c}\text { Turbidity } \\
\text { (FTU) }\end{array}$ & $\begin{array}{l}\text { Conductivity } \\
\qquad\left(\mu \mathrm{S} \mathrm{cm}^{-1}\right)\end{array}$ & $\mathrm{pH}$ & $\begin{array}{c}\text { Total solids } \\
\quad\left(\mathrm{mg} \mathrm{L}^{-1}\right)\end{array}$ \\
\hline Municipal effluent & $21-29$ & $47-66$ & $9-12$ & $575-602$ & $6.16-6.45$ & - \\
\hline Municipal pretreated & $127-465$ & $360-816$ & $67-151$ & 719-786 & $7.56-9.12$ & $470-630$ \\
\hline Landfill leachate & $447-638$ & $450-975$ & $85-184$ & $1850-5005$ & $7.70-8.42$ & $1300-3200$ \\
\hline
\end{tabular}

157 2.2. Experimental setup

158 The natural freezing of wastewater was done in a wind tunnel-like laboratory-scale apparatus 159 custom-made of a thermally insulated chest freezer. The arrangement enables simulation of 160 natural freezing conditions because the temperature and velocity of cooling air can be carefully 161 controlled. Fig. 1 shows the experimental setup for natural freeze purification of wastewaters. 162 Winter simulator apparatus with a similar set-up was used in our previous freezing experiments 163 with electrolyte solutions (Hasan et al., 2018). 


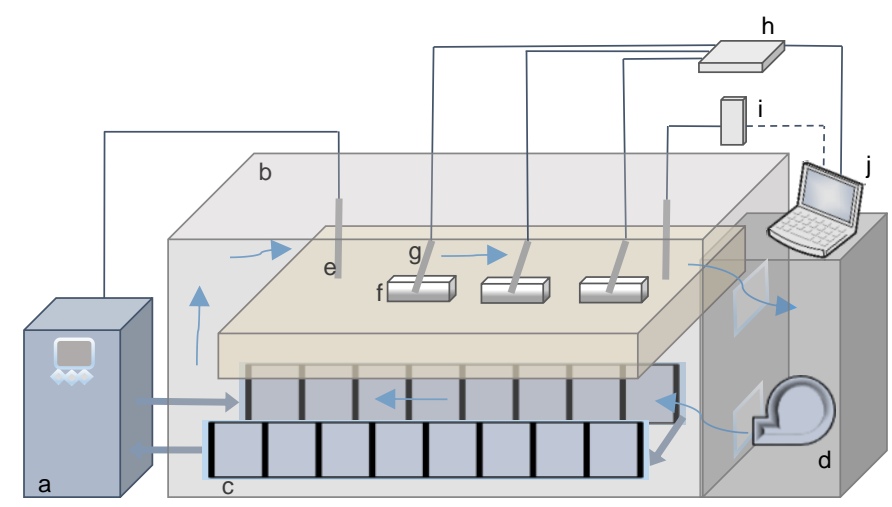

Fig. 1. Experimental setup for natural freeze purification of wastewaters: a) thermostat, b) chest freezer, c) heat exchangers, d) blower, e) temperature sensor, f) crystallizer vessels, g) PT 100 thermometers, h) data logger, i) anemometer and probe, j) computer.

168 Wastewater samples of $500 \mathrm{~mL}$ volume in plastic crystallizer vessels (volume of $\sim 710 \mathrm{~mL}$, edge dimensions $\sim 40 \mathrm{~mm} \cdot 87 \mathrm{~mm} \cdot 58 \mathrm{~mm}$ ) were allowed to freeze so that an ice layer formed on the upper surface of the wastewater. The water surface level was about $15 \mathrm{~mm}$ below the upper edge 171 of the vessel and, thus, the freezing area was $\sim 0.013412 \mathrm{~m}^{2}$. Heat losses through the other sides 172 of the vessels were avoided by thermal insulation when the vessels were installed inside the floor

173 level of the wind tunnel. The designed undercooling temperature degree $(\Delta T)$ was obtained by 174 circulating aqueous ethylene glycol coolant in heat exchangers. Air temperature in the wind tunnel 175 was controlled with a Lauda Proline RP 850 thermostat connected to a PT100 sensor measuring 176 air temperature. Cool air flow in the tunnel was produced with a blower. The air production of the 177 blower was adjusted with a frequency converter based on verified operating air flow velocity ( $\left.V_{\text {air }}\right)$ 178 measured with a Kimo VT100 (or VT210) anemometer (accuracies $\pm 0.1 \mathrm{~ms}^{-1}$ and $\pm 0.3^{\circ} \mathrm{C}$, 179 respectively). The temperatures of the wastewater samples in the vessels were measured with 180 PT100 platinum resistance thermometers. Temperature data was collected by Pico PT-104 Data 181 Logger (resolution $0.001^{\circ} \mathrm{C}$, accuracy $\pm 0.015^{\circ} \mathrm{C}$ ) and PicoLog software. 
182

183

184

185

186

187

188

189

190

191

192

193

194

195

196

197

198

199

200

201

202

203

204

205

\subsection{Freezing point depression test}

The freezing point depression (FPD) temperatures $\left(T_{f}\right)$ of different types of real wastewaters were determined to enable comparison of the undercooling temperature degree $(\Delta T)$ in the freezing experiments. The FPD test was executed with a simple cooling curve method in which measured temperature responses during cooling were plotted as a function of time. A $200 \mathrm{ml}$ wastewater sample was poured into a jacketed class reactor equipped with a magnetic stirrer. The circulation of ethylene glycol coolant in the jacket was controlled by a Lauda Proline RP 850 thermostatic unit. The temperatures of the water were measured with a PT100 sensor connected to the thermostat and the temperature data was logged to a file by a computer and Lauda Wintherm Plus software. The reference junction (calibration) of the thermostatic unit and probe was obtained with a pure ice and water mixture and verified using a mercury thermometer with a certificate of calibration.

\subsection{Experimental procedures and methods}

$500 \mathrm{~mL}$ samples of well-stirred wastewater were prepared for the freeze separation tests. Two or three replicates were prepared and frozen at the same time. Although the wastewater contained some visible solids, no pre-filtering or settling were used in order to simulate the process realistically. Before the freezing test, the water samples were allowed to cool to near to freezing temperature in a freezer room at $-18^{\circ} \mathrm{C}$ to avoid too high undercooling degree and to generate initial seed ice crystals for the freezing test. The precooling time needed varied between $30-50$ minutes depending on the wastewater type.

Before and immediately after the freezing test, the masses of the samples in the vessels were measured (balance Precisa BJ2200C, capacity $2200 \mathrm{~g}$, readability $0.01 \mathrm{~g}$ ) to determine the total mass loss, i.e. evaporated water, during the test. After the test period, the vessels were removed from the winter simulator and the remaining concentrated liquid (residual) and the formed ice layer 
were separated. The mass of the ice was measured as well as the volume of the concentrated

207 liquid. The average thickness $(\mathrm{mm})$ of the ice layer was determined by multipoint measuring with

208 a caliper. The ice piece was lightly rinsed with pure water cooled to near to $0{ }^{\circ} \mathrm{C}$ to avoid 209 adherence of external contaminants on the ice surface during manual sample handling. All ice 210 and residual concentrated liquid were collected and stored in a freezer at $-18{ }^{\circ} \mathrm{C}$ for further 211 analyses.

212 The ice layer growth rate is known to decrease during the freezing process as the heat insulating 213 effect of the ice layer increases with increasing layer thickness (Hasan et al., 2017). For this 214 reason, the freezing time was set at a constant 24 hours to be able to study how two controllable 215 variable parameters, i.e. air temperature and air flow velocity, affect ice growth rate and 216 separation efficiency. The basic parameters used were undercooling temperature degrees $\Delta T$ $2170.5,1.0,1.5,2.0$ and/or $3.0^{\circ} \mathrm{C}$ (or K), and air flow velocities $v_{\text {air }} 0.5,1.0,1.5,2.0$ and/or $3.0 \mathrm{~ms}^{-1}$. 218 Thus, at least nine different freezing conditions were assessed with each type of wastewater, see 219 the experimental design in Fig. 2.

a. Municipal effluent

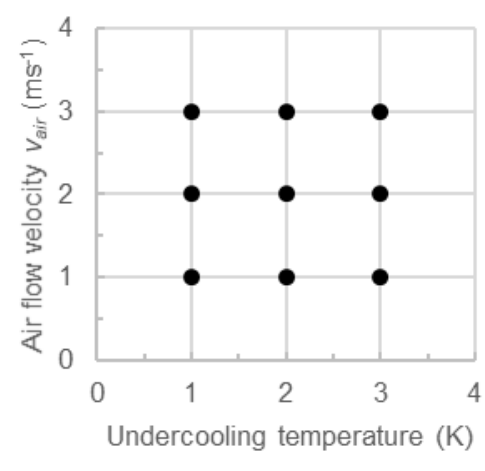

b. Municipal pretreated

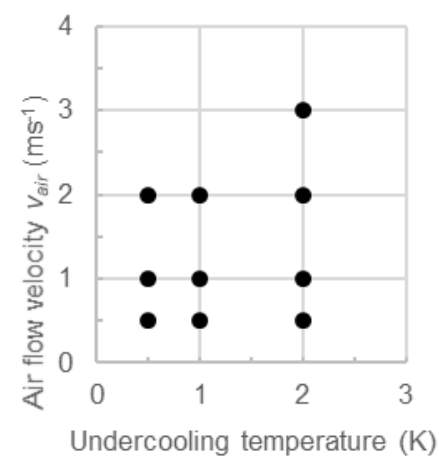

c. Landfill leachate

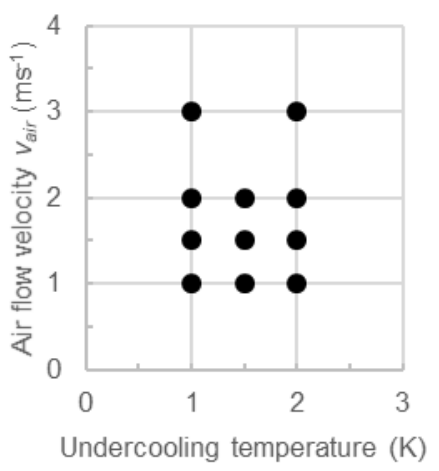

221 Fig. 2. Design of experiments for different wastewaters with the used combinations of undercooling temperature and 222 air flow velocity with freezing test time of 24 hours. 
223 Similar freezing tests were carried out with ultrapure water produced with an Elga PureLab water

224 purification system ( $\mathrm{TOC}<5 \mathrm{ppb}$, resistivity $18.2 \mathrm{M} \Omega \mathrm{cm}$ ) as blank samples for comparison.

225 Additionally, some tests were performed with different times: 5, 48 and 72 hours, and 226 temperatures: $\Delta T 5^{\circ} \mathrm{C}$ and $10^{\circ} \mathrm{C}$, to be able to survey the limitations of the experimental set-up

227 used, for example, regarding the effect of the obtained freezing ratio on the separation efficiency.

228 The assumption was that the separation efficiency will decrease if the freezing ratio is over $50 \%$

229 (i.e. half of the water is frozen) due to enrichment of the solution (Hasan and Louhi-Kultanen, 230 2016). The obtained freezing ratio (\%) was determined and confirmed by calculation of the 231 percentage of the ice mass formed from the initial water mass.

232 The average linear ice layer growth rate $\left(\mathrm{ms}^{-1}\right)$ was determined by dividing the average ice layer 233 thickness by the total freezing time. This calculation method enables comparison with previous 234 studies. The average ice mass growth rate, $\mathrm{g} \mathrm{h}^{-1} \mathrm{~m}^{-2}$, was calculated by dividing the measured 235 totally formed ice mass by the freezing time and surface area. The evaporation (or sublimation) 236 rate, $\mathrm{g} \mathrm{h}^{-1} \mathrm{~m}^{-2}$, can be determined in the same manner as the ice mass growth rate by dividing the 237 measured total mass loss by the freezing time and the surface area of the vessel.

238 Differences in the polycrystalline ice structures formed were observed macroscopically by 239 polarized light and microscopically (Olympus BH2-UMA) for visualization of the impurity inclusion, 240 veins and pockets in the ice. In these studies, however, the focus is on determination of 241 purification efficiency, and ice characteristics are not studied in detail. Thus, the primary use of 242 ice samples with limited volume was for chemical analyses.

\section{$243 \quad$ 2.5. Chemical analyses and methods}

244 The analysis methods used were chosen to indicate the general quality of the water and to 245 indicate the feasibility of freezing as an unselective purification method. When analyzing real wastewaters, the indirect measurements used in the present work, i.e. electrical conductivity and 
247 chemical oxygen demand (COD), give overall information about inorganic and organic matter 248 content, respectively. Ice and wastewater samples were analyzed using similar methods as used 249 in previous freezing studies to enable comparison of the achieved purification efficiency with 250 prevailing practices.

251 Before analysis, the melted ice samples and stored wastewater samples were kept at room 252 temperature to attain ambient temperature. A spectrophotometer $\mathrm{HACH} \mathrm{DR/2000} \mathrm{was} \mathrm{used} \mathrm{to}$ 253 determine the apparent color (PtCo, $455 \mathrm{~nm}$ ) and turbidity ( $\pm 2.0 \mathrm{FTU}, 450 \mathrm{~nm})$. The chemical 254 oxygen demand (COD, $\mathrm{mg} \mathrm{L}^{-1}$ ) was analyzed by spectrophotometer and a dichromate oxidation 255 method corresponding to APHA 5220 D (Greenberg et al., 1995) with a Spectroquant COD 256 reaction cell test measuring ranges $0-150 \mathrm{mg} \mathrm{L}^{-1}\left( \pm 2.7 \mathrm{mg} \mathrm{L}^{-1}, 420 \mathrm{~nm}\right)$ and $0-1500 \mathrm{mg} \mathrm{L}^{-1}( \pm 14$ $257 \mathrm{mg} \mathrm{L}{ }^{-1}, 620 \mathrm{~nm}$ ). A Consort C3040 multi-parameter analyzer was used to measure $\mathrm{pH}$ and 258 electrical conductivity (probe with temperature compensation, cell constant $1.0 \mathrm{~cm}^{-1}$, range 0.001 $259100 \mathrm{mS} \mathrm{cm}^{-1}$ ). Dry matter content as total solids (TS, $\mathrm{mg} \mathrm{L}^{-1}$ ) was determined by an evaporation260 weighing method corresponding to APHA 2540 B (Greenberg et al., 1995) for initial wastewater 261 samples. Almost all ice samples had to be excluded because of limited liquid volumes. As the 262 quality of raw wastewater changes even during short cool storing, the initial wastewater used was 263 analyzed for every experiment. Purification efficiency $E(\%)$ was calculated with Equation 1:

$$
E(\%)=100 \cdot\left(\frac{C_{w w}-C_{i c e}}{C_{w w}}\right)
$$

where $C_{w w}$ is the concentration or other measured value in the initial wastewater and $C_{i c e}$ the concentration or other measured value in the ice. 
267

268

269

270

271

272

273

274

275

276

277

278

279

280

281

282

283

284

285

286

287

288

289

\section{Results and discussion}

\subsection{Freezing point depression}

The determined freezing point depression (FPD) temperatures and obtained supercooling temperatures of the studied wastewaters are presented in Table 2. It is important to define these temperatures as temperature difference is the driving force for the ice crystallization process. Freezing temperature and the degree of supercooling used affect the ice nucleation and ice crystal growth. The FPD temperatures of the municipal wastewaters, effluent and pretreated wastewater were quite similar. The FDP temperature was slightly lower with pretreated wastewater and the supercooling degree quite moderate, 2 to $3^{\circ} \mathrm{C}$. As expected, landfill leachate showed approximately four times lower FPD temperatures than municipal wastewaters, -0.220 ${ }^{\circ} \mathrm{C}$ at their lowest, because landfill leachate contains more ionic matter. An example of a cooling curve recorded in an FPD test for landfill leachate is presented in Fig. 3. It was of importance to determine the FPD temperature, as FPD of wastewaters is rarely studied. The FPD seemed to indicate the total impurity of wastewater rather sensitively, especially inorganic matter.

Table 2. Determined freezing point depression temperatures and supercooling temperatures of the studied wastewaters.

\section{Municipal effluent Municipal pretreated Landfill leachate}

\begin{tabular}{lccc}
\hline FPD temperature $\left({ }^{\circ} \mathrm{C}\right)$ & $-0.035 \ldots-0.048$ & $-0.040 \ldots-0.060$ & $-0.185 \ldots-0.220$ \\
Supercooling temperature $\left({ }^{\circ} \mathrm{C}\right)$ & $\mathrm{n} / \mathrm{a}$ & $-1.860 \ldots-3.010$ & $-2.880 \ldots-3.350$ \\
\hline
\end{tabular}

With the studied wastewaters, the freezing point depression was not very significant compared to common dilute salt solutions. More important was the variation in FPD temperatures with the same type of wastewater. The FPD temperature of the wastewaters varies because of the differing composition of the sampled raw wastewater batches. The FPD temperature was also found to change during storage of the wastewater, presumably due to decomposition of impurities in the water. Although the FPD temperature differences between the different wastewaters 
290

291

292 energy consumption of the utilized freezing process.

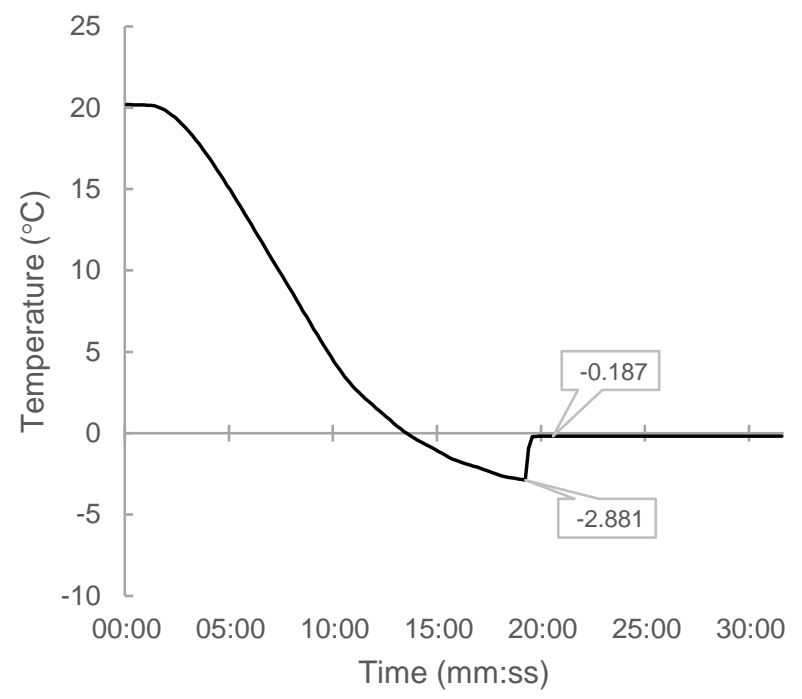

293

294

295

296

297

298 Usually, the crystal growth began from ice crystal seeds that had formed during the precooling in 299 a freezer. Ice crystal growth continued, forming needle-, dendrite- and/or platelet-like ice on the 300 surface of the water, until the surface was totally covered with a very thin ice layer. The initial 301 dendritic tree-like growth on the liquid surface is presumably due to simultaneous evaporation of 302 water and freezing, and the needle-like ice forms due to seeding and quick cooling (Mullin, 2001).

303 Thin ice formations were sometimes difficult to observe visually (and by a camera) because of 304 their transparency, see Fig. 5a and 5d. After surface ice growth, the ice layer continued growing 305 towards the liquid water. 
306 The measured temperatures of the water under the ice were seen to plateau near the determined

307 freezing temperatures or at lower temperatures with minor supercooling, as can be seen in the 308 freezing temperature profiles of the different waters under the same cooling conditions $(\Delta T 2 \mathrm{~K}$ 309 and $\left.v_{\text {air }} 2 \mathrm{~ms}^{-1}\right)$ in Fig. 4. With lower air temperatures $\left(<-3^{\circ} \mathrm{C}\right)$ and higher air velocities $\left(>3 \mathrm{~ms}^{-1}\right)$ 310 the temperature of the water began to decrease with freezing time due to more intense forced 311 convection. It was noticed, however, that the surface started to freeze before attaining equilibrium 312 freezing temperature, and sometimes even at $0^{\circ} \mathrm{C}$, as the temperature probe measured the 313 average bulk temperature of the water but not the temperature at the ice-water interface.

314 Controlled precooling of the water samples proved to be difficult and the temperature of the replica 315 samples varied at the beginning of the freezing test despite similar preparation for the same time. 316 As a consequence, the starting temperature of the freezing tests varied from 0.75 to $2.25^{\circ} \mathrm{C}$.

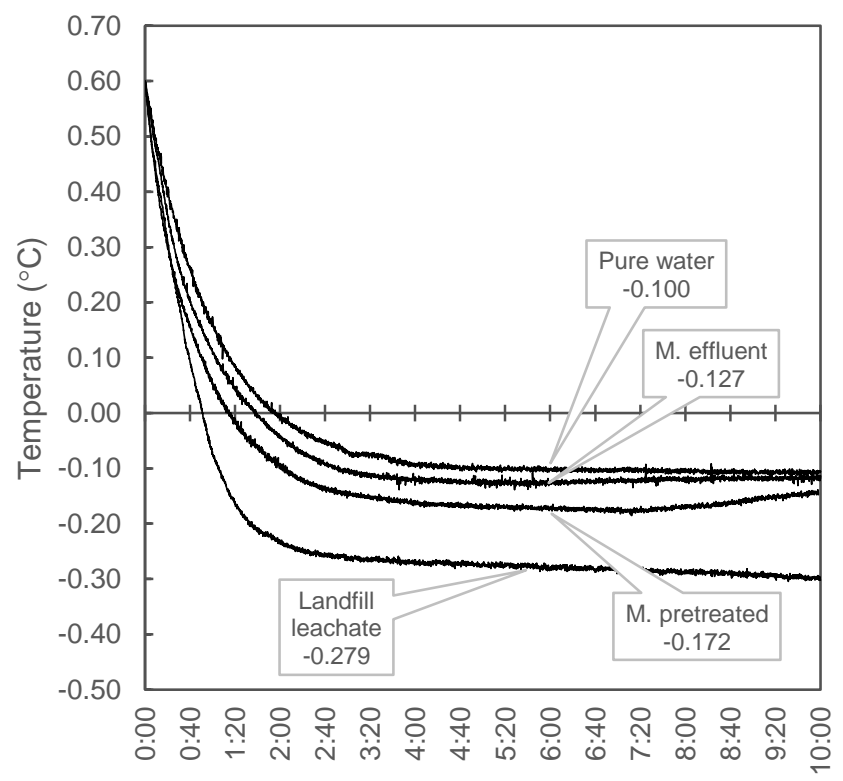

Freezing time (hh:mm)

318 Fig. 4. Temperature profiles of purified water, effluent wastewater, pretreated wastewater and landfill leachate in the 319 crystallization vessel in the wind tunnel during 10 hours' freezing, conditions of $\Delta T 2 \mathrm{~K}$ and $v_{\text {air }} 2 \mathrm{~ms}^{-1}$. Temperatures $320 \quad\left({ }^{\circ} \mathrm{C}\right)$ within 6 hours freezing marked in the curves. 
321 Freezing time of approximately two hours was required to form an ice layer fully covering the 322 upper liquid surface. With lower temperatures, development of the ice layer happened a little 323 faster. An exception here was that in some cases, mostly with low air velocity of $0.5 \mathrm{~ms}^{-1}$ or 324 undercooling temperature of $0.5 \mathrm{~K}$, no uniform ice layer was formed. In other cases, only two 325 thirds or half of the upper surface was frozen after $24 \mathrm{~h}$ freezing time and the temperature of the 326 water in the vessel remained higher than the freezing temperature and sometimes even above 0 $327{ }^{\circ} \mathrm{C}$. Many of the ice pieces were wedge-shaped with a quite planar upper surface and the thinner 328 end edge facing towards the air flow: ice under the air inlet was thinner than the ice layer under 329 the air outlet. This exceptional shape was most likely due to the experimental setup, i.e. local 330 turbulent air flow conditions. Therefore, ice growth rates were primarily assessed by measured 331 ice mass and ice layer thickness was calculated as the average thickness of multiple 332 measurement points. Some suspended solids settled on the bottom of the vessel during freezing 333 of more concentrated wastewater, as can be seen in the municipal pretreated wastewater in Fig. $3345 b$. 


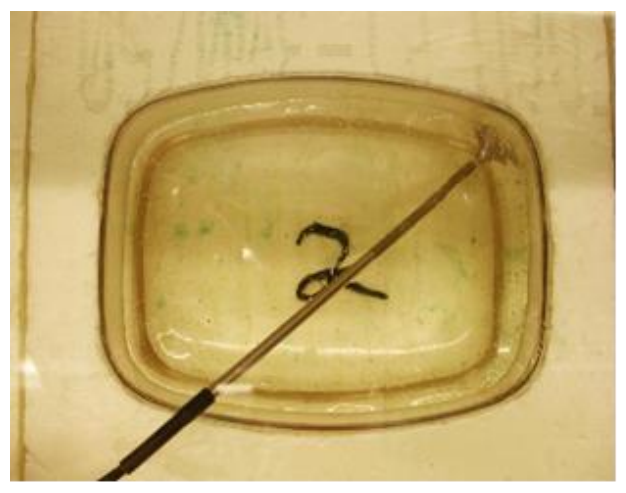

a

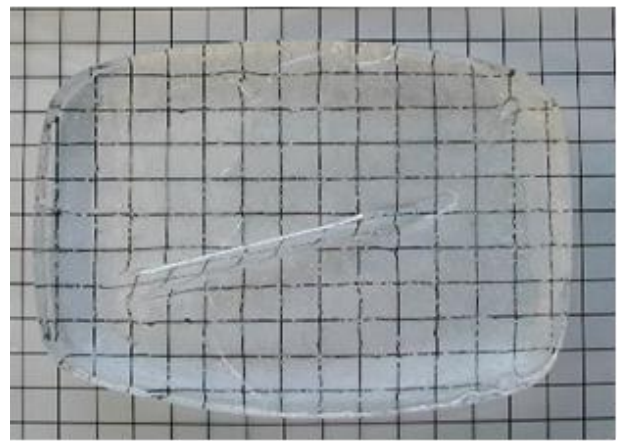

c

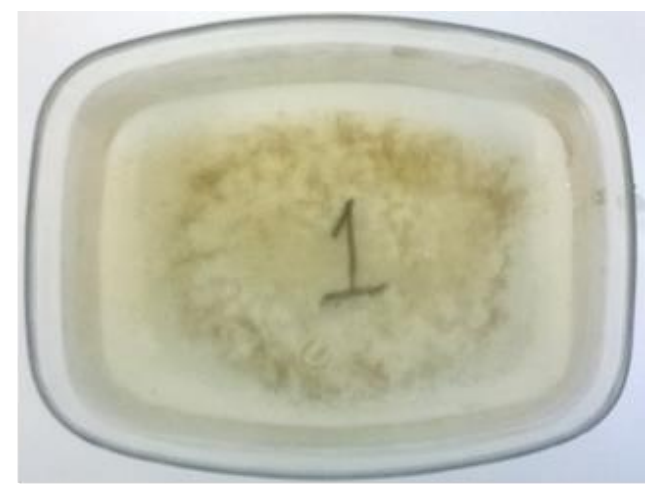

b

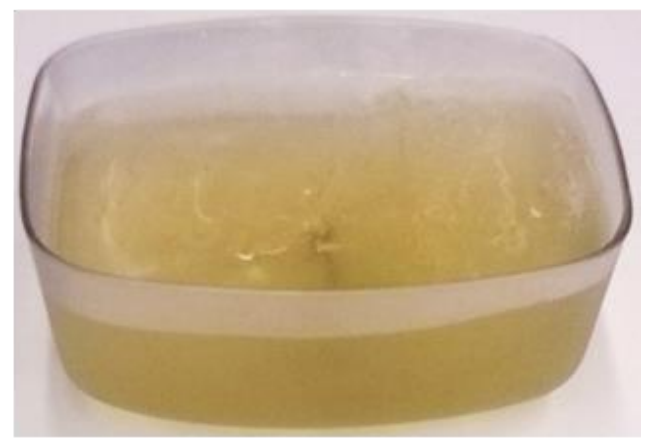

d

Fig. 5 a) Ice and municipal effluent in the crystallizer vessel with the temperature probe: b) some suspended solids of municipal pretreated wastewater settled on the bottom of the vessel during freezing - notice the pattern; c) an ice piece formed from municipal effluent, measure grid $1 \mathrm{~cm} \times 1 \mathrm{~cm}$; and d) ice and landfill leachate in the crystallizer vessel.

\subsection{Formed ice}

All the ice layer samples seemed to have relatively high mechanical strength compared, for

341 example, with the fairly soft ice formed from salt solutions in previous studies. Thicker ice pieces

342 could not be broken without tools. Some small bubbles or thin veins inside the ice were noticed

343 (see Fig. 5c) but no regular patterns. The upper surface of the ice was mostly planar (with some

344 mild humps and bumps) and clear, and no accumulated solid matter could be seen. The bottom

345 of the ice was also mostly planar, although in some cases the bottom had spiky (small needles)

346 ice formed by higher growth rates. However, no regular patterns, e.g. dendritic platelets, were 347 observed. 
348 The visual color of the ice varied from very transparent ice for municipal effluent to shades of a 349 yellow brownish color for landfill leachate ice. The values of apparent color and turbidity measured 350 in the melt ice did not always match visual observations; ice with high measured values could 351 look misleadingly clear and transparent. Generally, no explanatory correlation could be found 352 between the visual characteristics of the ice and the purification efficiency. In most cases, the 353 purified wastewater water (melt ice) smelled like dilute wastewater, i.e., it was not odorless, even 354 though it looked like clear ice. Microscopic observation revealed clear differences in ice 355 characteristics (Fig. 6). Whereas fairly clean ice showed as blank spaces with clear ice crystal 356 boundaries (Fig. 6a), the municipal effluent ice clearly contained impurity inclusions (Fig. 6b). In 357 addition, landfill leachate ice incorporated small solid grains (Fig. 6c). It was difficult to observe 358 the ice crystal boundaries of impure polycrystalline ice and identify any impurities (fibers, micro359 organisms, microplastics etc.) due to overlaps in the structure.

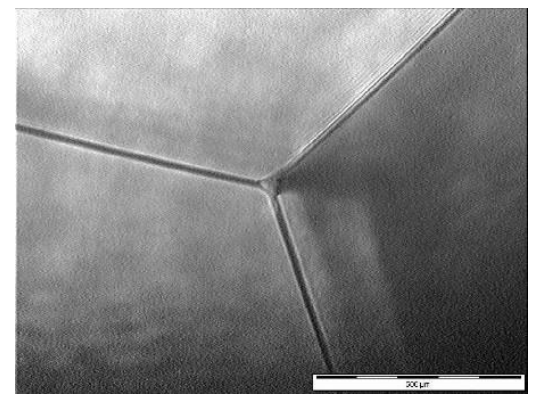

a

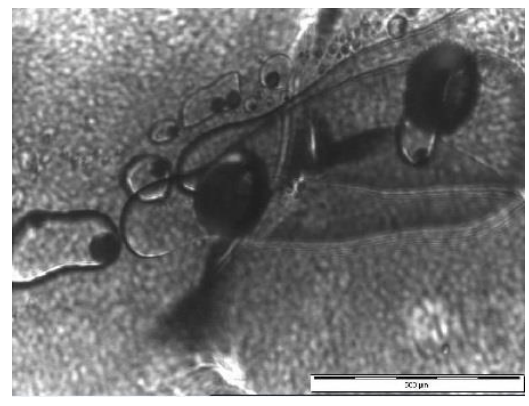

b

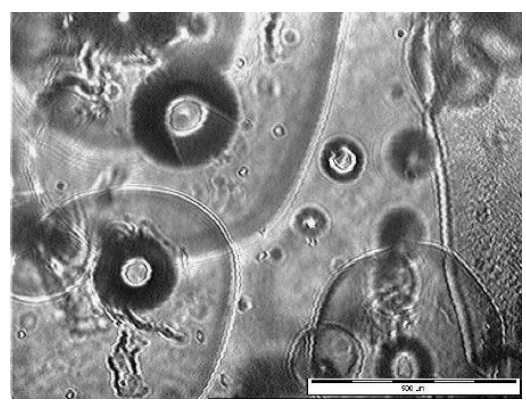

C

360 Fig. 6. Microscopic characteristics of ice formed with different waters and under different freezing conditions 361 (undercooling degree temperature and air flow velocity): a) pure water $\left(1 \mathrm{~K}, 3 \mathrm{~ms}^{-1}\right)$ b) municipal effluent ice $\left(1 \mathrm{~K}, 1 \mathrm{~ms}^{-}\right.$ ${ }^{1}$ ) and c) landfill leachate ice $\left(1 \mathrm{~K}, 2 \mathrm{~ms}^{-1}\right)$, bar scale $500 \mu \mathrm{m}$, magnification $5 \mathrm{x}$.

\subsection{Ice growth rate}

Some correlation was found between the wastewater freezing results and the freezing conditions in the winter simulator. An almost linear function for ice mass growth rate $\left(\mathrm{g} \mathrm{h}^{-1} \mathrm{~m}^{-2}\right)$ as a function of air flow velocity $\left(\mathrm{ms}^{-1}\right)$ with different undercooling temperatures $(\mathrm{K})$ was obtained based on 
$368 R^{2}$ (the coefficient of determination) varying from 0.856 to 0.998 . As expected, freezing conditions, 369 i.e. air flow velocity and temperature, directly affected the ice growth rate, as can be seen in Fig. $3707 \mathrm{a}, \mathrm{b}$ and $\mathrm{c}$, for different wastewaters, whereas the effect of wastewater quality can be considered 371 to be more moderate or minor. When all the mass growth rates of the different wastewaters and 372 air velocities with undercooling temperatures $1 \mathrm{~K}$ and $2 \mathrm{~K}$ were fitted in the same linear model 373 (Fig. $7 \mathrm{~d}$ ) the $\mathrm{R}^{2}$ values were still at a good level: 0.898 with $\Delta T 1 \mathrm{~K}$ and 0.783 with $\Delta T 2 \mathrm{~K}$. The 374 lines are very parallel with almost equal slopes (236 and 237).

375 Deviations and lower $\mathrm{R}^{2}$ values are more likely due to the experimental setup and measurement 376 conditions, that is, vibration of the chest freezer, humidity differences or minor human errors etc., 377 than the wastewater composition. As was previously noticed for ice pieces formed with low 378 undercooling temperature of $0.5 \mathrm{~K}$, the air-cooled freezing process is very easily influenced by 379 factors that are difficult to measure. This issue can be seen in Fig. $7 \mathrm{~b}$, where the line for $0.5 \mathrm{~K}$ 380 undercooling indicates higher ice mass growth rates than $1 \mathrm{~K}$ undercooling. A part of the water 381 surface was open to air and the increased air flow intensified the ice growth, both as regards mass 382 and ice layer thickness $\left(\mathrm{ms}^{-1}\right)$.
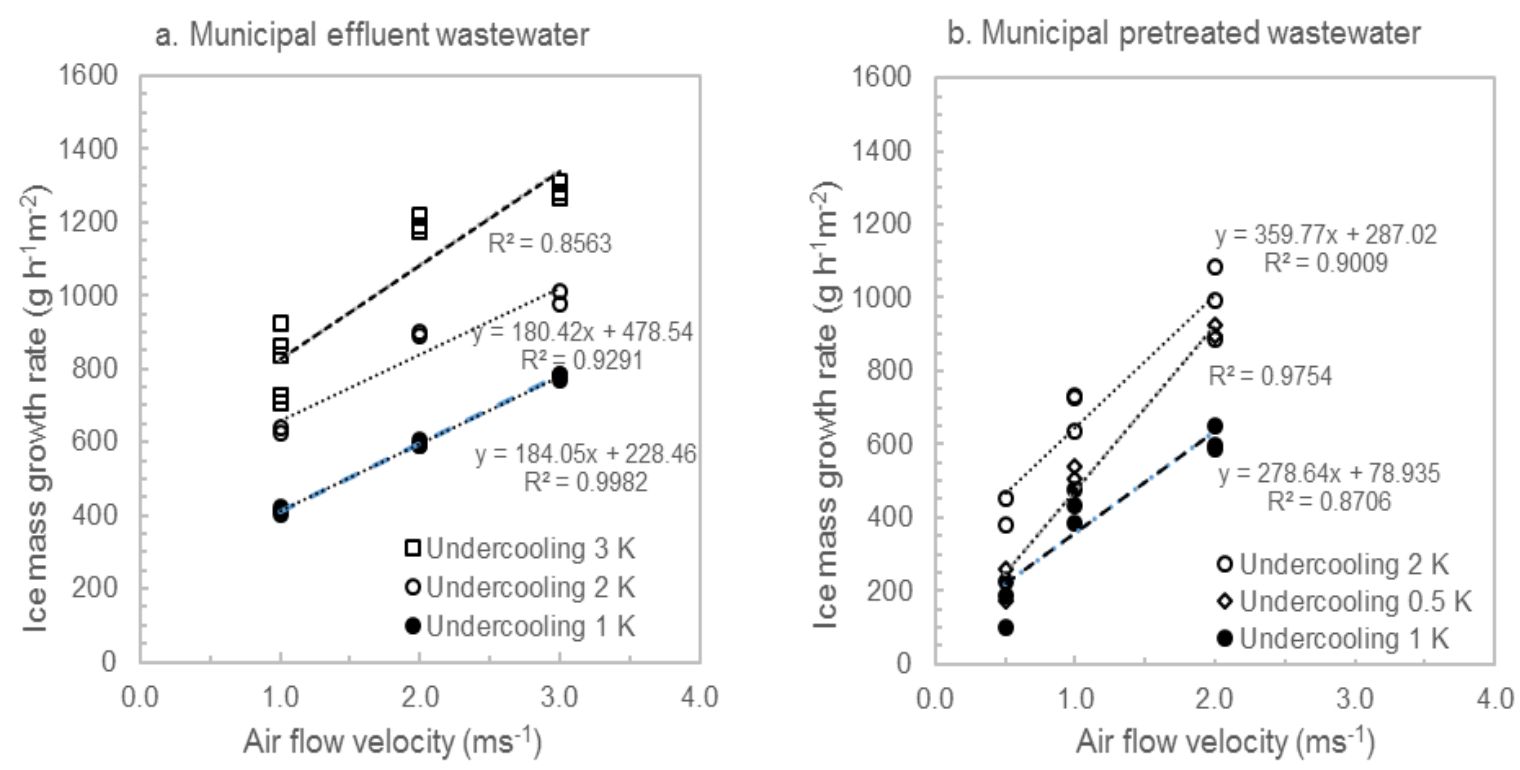

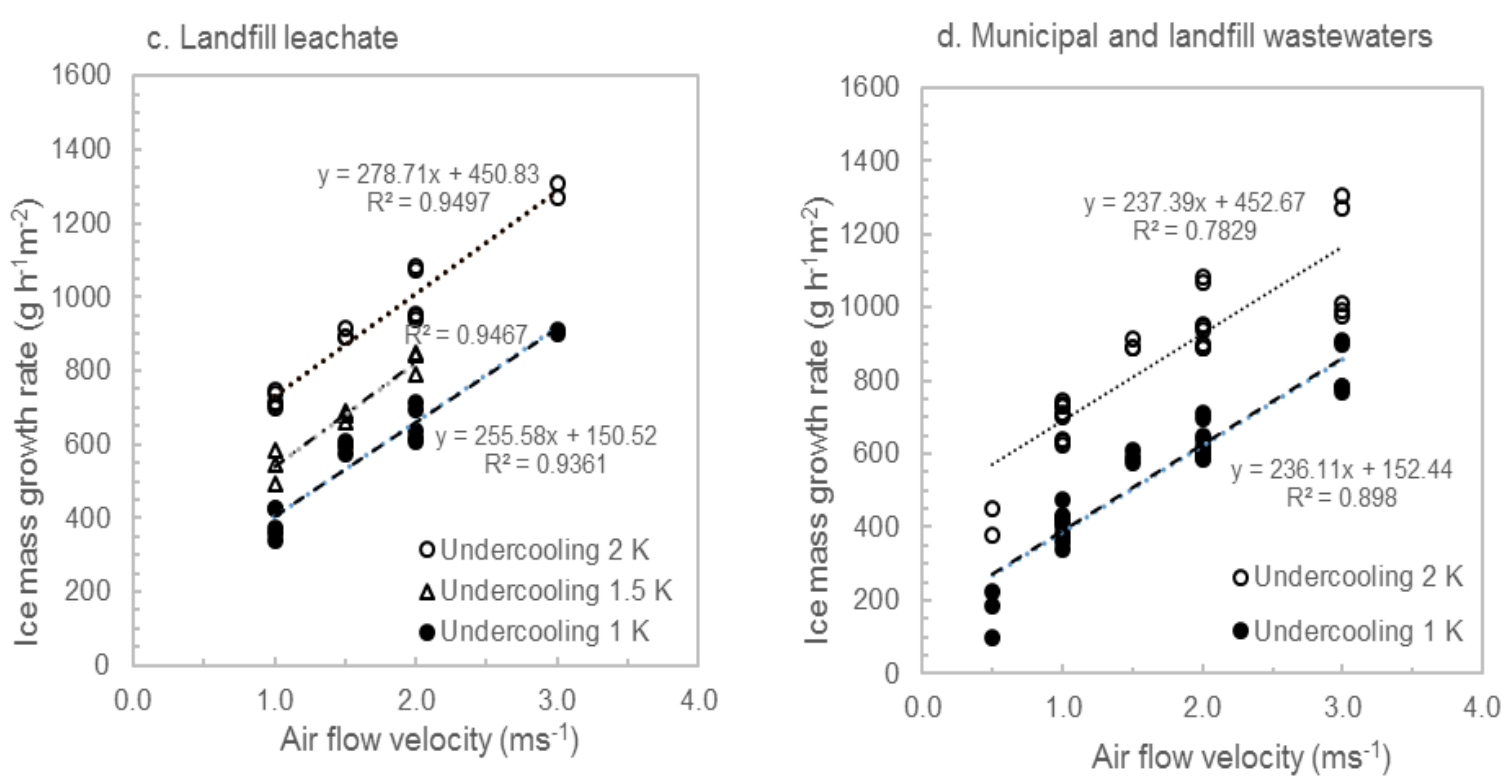

383

384

385

386

Fig. 7. Ice mass growth rates as a function of air flow velocity with different undercooling degree temperatures: a) effluent, b) pretreated wastewater, c) landfill leachate and d) the combined results of all municipal and landfill wastewaters with undercooling temperatures 1 and $2 \mathrm{~K}$. Linear fittings, $\mathrm{N}=6-28$.

Based on the results of these freezing experiments and the simple model used for the freezing conditions, it can be seen that the undercooling temperature defines the base level of the ice growth rate on the intersection of the $y$-axis and the air velocity gives the coefficient or impact factor for the intensity of the growth rate by the slope of the linear line (Fig. 7d). For example, with conditions $\Delta T=1 \mathrm{~K}$ and $v_{\text {air }}=1 \mathrm{~ms}^{-1}$, the average mass growth rate (i.e. the ice mass production) was $389 \mathrm{~g} \mathrm{~h}^{-1} \mathrm{~m}^{-2}$. When air velocity was increased from $1 \mathrm{~ms}^{-1}$ to $2 \mathrm{~ms}^{-1}$, the ice mass growth rate increased by $236 \mathrm{~g} \mathrm{~h}^{-1} \mathrm{~m}^{-2}$ to $625 \mathrm{~g} \mathrm{~h}^{-1} \mathrm{~m}^{-2}$. With undercooling temperature of $2 \mathrm{~K}$, the growth rate behaved in the same way. The same linearity can be found with ice layer growth rates $\left(\mathrm{ms}^{-1}\right)$. Verification of the presumption of linearity with lower freezing temperatures vs. growth rates as a function of air flow velocity could not be examined due to limitations in the experimental setup used.

Comparison of the ice growth rate results of the present work and previous studies reported in literature is problematic because most research has been carried out in very different conditions, 
399 i.e. with much colder temperatures and lower air flow velocities. However, the ice layer growth 400 rates obtained in our previous study with electrolyte solutions (nickel sulphate) correspond 401 somewhat with the growth rates in freezing of wastewater found in this work. For similar conditions $402\left(\Delta T=1 \mathrm{~K}, v_{\text {air }}=2 \mathrm{~ms}^{-1}, 24 \mathrm{~h}\right)$, the salt solutions had an average ice layer growth rate of $\sim 2.5 \cdot 10^{-}$ $403{ }^{7} \mathrm{~ms}^{-1}$ (Hasan et al., 2018) and in this study the average rate was $2.05 \cdot 10^{-7} \mathrm{~ms}^{-1}$.

\section{3.5. Purification efficiency}

405 As previously described in section 3.4., the ice growth rate results from factors determining the 406 freezing conditions, i.e. air temperature and velocity, and similar growth rate can be obtained with 407 various combinations of these parameters. Therefore, when considering the purification efficiency 408 of different wastewaters, it is more meaningful to compare the ice growth rate than the freezing 409 conditions directly.

410 The calculated results showed that the greater the ice growth rate, the lower the purification

411 efficiency. The effect is clearly seen in more concentrated wastewaters with inorganics, like landfill

412 leachate, see Fig. 8. With a lower ice mass growth rate of $400 \mathrm{~g} \mathrm{~h}^{-1} \mathrm{~m}^{-2}$, the average purification 413 efficiency was near to $90 \%$. The efficiency decreased to $60-70 \%$ when the ice mass growth rate 414 increased to $800 \mathrm{~g} \mathrm{~h}^{-1} \mathrm{~m}^{-2}$. With the effluent, no obvious correlation between ice growth and 415 purification could be found, partly due to limitations in the analysis methods when used for very 416 dilute wastewaters. However, the average purification efficiency was mainly in the range $75-90 \%$ 417 for all water quality indicators and the effect of higher ice mass growth rate on purification can 418 thus be considered to be less significant with dilute effluent. 

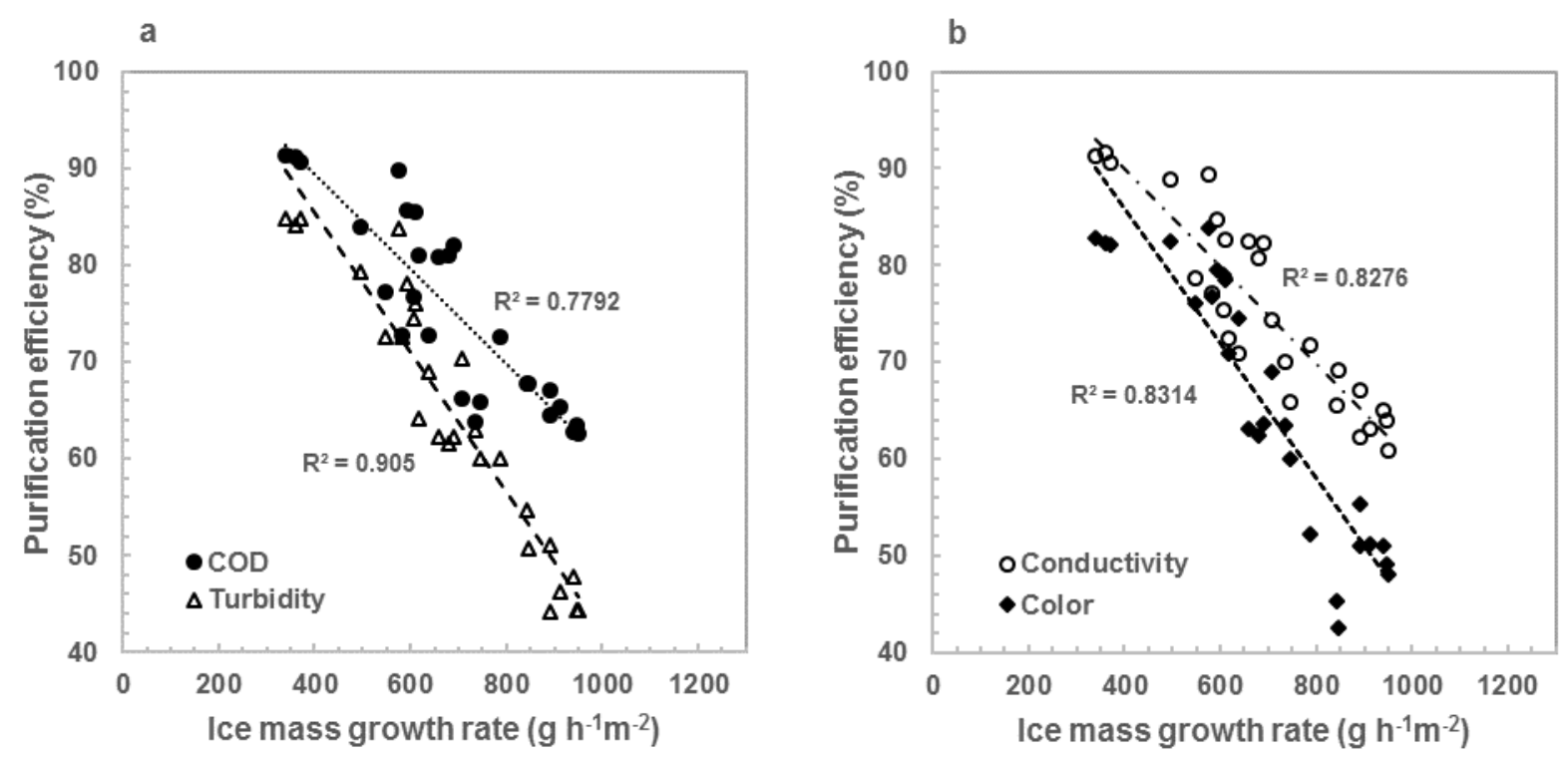

419 Fig. 8. Purification efficiencies of a) COD and turbidity and b) conductivity and color with different ice mass growth 420 rates in freezing tests of landfill leachate. Linear fittings, $N=27$.

421 With pretreated wastewater, the effect of ice mass growth rate was not as evident as with landfill 422 leachate since the decrease in purification efficiency related to an increase in ice mass growth is 423 much lower and $R^{2}$ values are somewhat lower, see the trend lines in Fig. 9. For instance, lower 424 ice mass growth rates of 200 and $400 \mathrm{~g} \mathrm{~h}^{-1} \mathrm{~m}^{-2}$ showed average purification efficiencies of around $42590 \%$ and a higher growth rate of $800 \mathrm{~g} \mathrm{~h}^{-1} \mathrm{~m}^{-2}$ resulted in efficiencies slightly under $80 \%$. 426 Unexpectedly, very fast freezing of municipal pretreated wastewater over 5 hours' freezing time, $427 \Delta T=10 \mathrm{~K}, v_{\text {air }}=0.5 \mathrm{~ms}^{-1}$ and growth rate of $\sim 800 \mathrm{~g} \mathrm{~h}^{-1} \mathrm{~m}^{-2}$ also resulted in $90 \%$ COD reduction. 428 The difference between the test result with the same undercooling degree and a higher air flow 429 velocity of $1 \mathrm{~ms}^{-1}$ and growth rate of $\sim 1800 \mathrm{~g} \mathrm{~h}^{-1} \mathrm{~m}^{-2}$ is noteworthy, as it resulted in $76 \%$ COD 430 reduction. The more extreme freezing conditions should be investigated further, as ice mass 431 production over time might be a significant factor in utilization of natural freezing processes. 


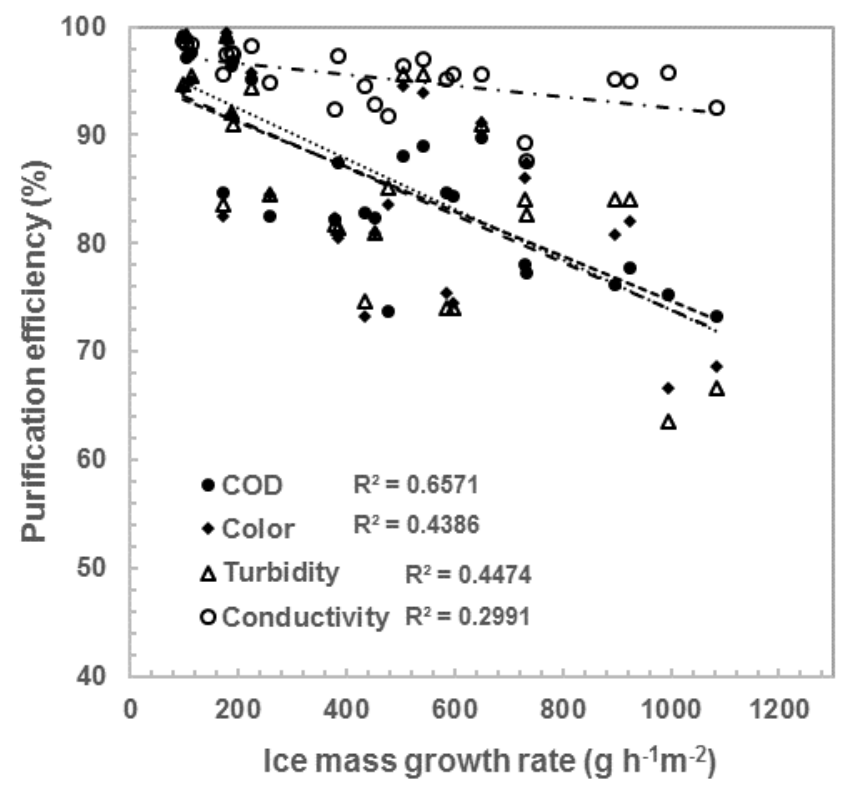

433 Fig. 9. Purification efficiencies of COD, color, turbidity and conductivity with different ice mass growth rates in freezing 434 tests of municipal pretreated wastewater. Linear fittings, $N=25$. Trend lines of COD, color and turbidity are almost 435 parallel.

436 When municipal pretreated wastewater was frozen under conditions of $\Delta T=1 \mathrm{~K}$ and $v_{\text {air }}=0.5 \mathrm{~ms}^{-}$

$437{ }^{1}$, the highest purification efficiencies, $>95 \%$, were obtained for all water quality indicators with 438 very low ice growth rates. Longer freezing time of 72 or $48 \mathrm{~h}$ did not show any effect on purification 439 efficiency, i.e. the efficiency was at the same level as in $24 \mathrm{~h}$ freezing. These conditions were not 440 tested with landfill leachate, since using a velocity of $0.5 \mathrm{~ms}^{-1}$ (or a $0.5 \mathrm{~K}$ undercooling degree) 441 was earlier seen to cause unexpected deformations in the ice pieces. Very low ice growth rates 442 should be tested with an improved experimental set-up. However, based on these results, it can 443 be concluded that very high purification efficiencies can be achieved with very slow freezing.

444 The tendency of wastewaters of different concentrations to form more impure ice with an 445 increasing ice growth rate can be seen in Figs. 7, 8 and 9. When comparing municipal pretreated 446 wastewater with more concentrated landfill leachate, it is noticed that the effect of higher ice mass 447 growth rate on purification efficiency is much stronger with landfill leachate, i.e. the direction of 
448 the trend line is decreasing and the incline is steeper (Fig. 8). The same trend was seen also in 449 previous studies for freezing salt solutions of different concentrations when plotting the purification 450 efficiency in terms of the effective distribution coefficient as a function of the ice layer growth rate 451 (Hasan and Louhi-Kultanen, 2015, 2016; Hasan et al., 2018). Based on this observation, it can 452 be deduced that the type of wastewater (i.e. impurity concentration) can affect the ice 453 crystallization process and the impurity rejection efficiency.

454 Despite the very different wastewaters and freezing conditions, the purification efficiencies obtained in the present work are rather similar to previous natural freeze crystallization studies reported in literature. In the present study, COD concentrations in the initial wastewaters were $21-638 \mathrm{mg} \mathrm{L}^{-1}$ for freezing temperatures of $\sim-0.5$ to $-3.2{ }^{\circ} \mathrm{C}$ with a freezing ratio $<50 \%$. Yin et al. 458 (2017) studied highly concentrated effluent (20 000-30 $000 \mathrm{mg} \mathrm{L}^{-1}$ COD) containing organic 459 pharmaceutical intermediates. Their study obtained a COD removal efficiency of $70-90 \%$ with an 460 ice formation ratio of $20 \%$ at temperatures of -4 to $-12{ }^{\circ} \mathrm{C}$. Gao et al. (2009) reported $90-96 \%$ 461 COD and TOC reduction in freezing of petroleum refiner effluent with initial COD concentration of $462767 \mathrm{mg} \mathrm{L}^{-1}$ (freezing ratio $70 \%$ at -10 and $-25^{\circ} \mathrm{C}$ ). Soluble pollutants of urban wastewaters were 463 studied by Lorain et al. (2001) using a non-air-cooled freezing setup. Near 90\% efficiency was 464 attained (freezing ratio $64 \%,-7^{\circ} \mathrm{C}$ ) for freeze crystallization of the wastewater after primary 465 settling. In our previous study (John et al., 2018), comparable separation efficiencies of $65-90 \%$ 466 were attained for naturally frozen ice in wastewater basins of a mining site.

467 When the results obtained in this study are compared with current regulations for municipal 468 wastewater treatment plants, the best purification efficiencies achieved can be considered to be 469 at a good level. For instance, the environmental permit of the Toikansuo wastewater treatment 470 plant, which is the source of the wastewater samples, limits the COD concentration (average of 471 quarterly sampled results) of the effluent to $70 \mathrm{mg} \mathrm{L}^{-1}$, i.e. the minimal acceptable purification 472 efficiency of the plant is $80 \%$. In this study, this requirement was met in freeze crystallization of 
473 municipal pretreated wastewater at lower ice growth rates, where COD concentration varied from

$474<3$ to $41 \mathrm{mg} \mathrm{L}^{-1}$. It is known that regulations are going to become more stringent in the near future

475 and many wastewater treatment plants are already exceeding minimal requirements. Indeed, the

476 old Toikansuo treatment plant has attained COD concentration in effluent of 30-40 $\mathrm{mg} \mathrm{L}^{-1}$, giving

477 a purification efficiency of $95 \%$.

\section{$478 \quad$ 3.6. Further remarks}

479 The effect of the acidity or alkalinity of aqueous solutions is rarely studied in freeze crystallization 480 as $\mathrm{pH}$ is assumed to have very minor or negligible effect on the freezing process, although Gao 481 et al. (1999) suggested that $\mathrm{pH}$ has an effect on freezing temperature and nucleus concentrations 482 of wastewaters. However, $\mathrm{pH}$ is a relevant factor when evaluating the quality of the effluent to be 483 discharged into the environment.

484 In the freezing experiments in this work, it was noticed that the $\mathrm{pH}$ values of the melted ice or 485 concentrated residual may be significantly different from the $\mathrm{pH}$ of the initial wastewater 486 (Supplementary material, Fig. A.1). The $\mathrm{pH}$ value of the ice can be either higher or lower than that 487 of the initial wastewater depending on the source of the wastewater. Generally, an increase of $488 \quad 0.5-1.0 \mathrm{pH}$ (e.g. increase from $\mathrm{pH} 7.7$ to 8.7) was noticed with landfill leachate freezing. Then 489 the highest $\mathrm{pH}$ values of ice were still allowable. The largest decrease, from $\mathrm{pH} 8.8$ to 6.5 , was 490 detected with pretreated municipal wastewater, although the $\mathrm{pH}$ of the ice remained at a rather 491 neutral level as the initial $\mathrm{pH}$ of the wastewater was quite high. The most remarkable decrease in $492 \mathrm{pH}$ was found with effluent. The lowest final $\mathrm{pH}$ value of effluent melt ice was $4.2 \mathrm{pH}$ (for effluent 493 with a quite low initial $\mathrm{pH}$ of $<6.5 \mathrm{pH}$ ).

494 Low alkalinity of the effluent because of earlier bio-chemical water treatment could explain the 495 decrease in $\mathrm{pH}$. However, if chemicals are not added to the water in the freeze crystallization, the 496 changes in hydrogen-ion concentration must occur internally. As the $\mathrm{pH}$ value changes during the 
497 freezing processes were rather chaotic, it is speculated that the changes in $\mathrm{pH}$ might be related

498 to decomposition of organic matter in the wastewater resulting in carbon dioxide release to the

499 water. Based on the present study, no direct relationship between $\mathrm{pH}$ and purification efficiency

500 could be found. Changes in $\mathrm{pH}$ and the factors causing such changes during the freezing process

501 should be studied more comprehensively, because effluent whose $\mathrm{pH}$ deviates significantly from

502 the recommended $\mathrm{pH}$ of 6.5 - 8.5 (Tchobanoglous et al., 2003) can not be discharged or recycled

503 without neutralization.

504 The undercooling temperature and air flow velocity affected the rate of evaporation (or 505 sublimation), $\mathrm{g} \mathrm{h}^{-1} \mathrm{~m}^{-2}$. The effect on evaporation of temperature alone was minor, but combined 506 with air flow velocity, lower temperature increased the evaporation, as shown for instance in Fig. 50710 with landfill leachate freezing tests. The determined amount of water evaporation/sublimation 508 mass during the freezing tests varied from $7-15 \%$ of the formed ice mass. Hence, evaporation 509 proved to be a significant factor in mass balance of the freeze purification process design and 510 greater attention should be paid to evaporation in future natural freezing experiments.

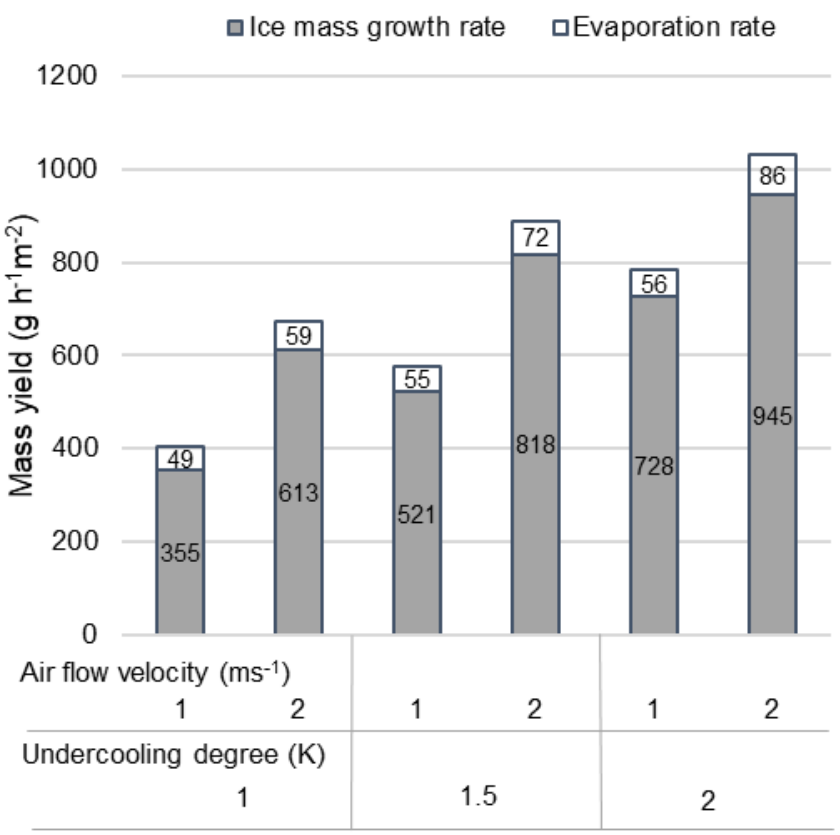


512 Fig. 10. Average evaporation rates (determined by mass loss measurements) and ice mass growth rates in landfill

513 leachate freezing at undercooling temperatures $1,1.5$ and $2 \mathrm{~K}$ and air flow velocities 1 and $2 \mathrm{~ms}^{-1}$.

514 Based on this study, natural freeze crystallization of wastewaters was found to be a rather 515 complex process. Many parameters affect the system, which made precise control of process 516 conditions challenging and led to unpredictability in the purification efficiency attained. The 517 required effluent quality can be achieved by one-time natural freezing if the wastewater is frozen 518 very slowly. However, low ice growth rates generally require a low temperature gradient, i.e. rather 519 high freezing temperatures, and consequently, a very large freezing surface as well as long 520 freezing time are needed to maintain sufficient ice mass production. Thus, considerable

521 challenges could be faced in optimization of process design, i.e. when resolving the optimal 522 freezing ratio and recycling of concentrated wastewater in the process. Consequently, multiple 523 sequenced freezing processes are likely to be more efficient than simple one-time freezing. The 524 results of ice mass production and purification efficiencies gained in this study are of importance 525 in future studies when realistically evaluating the possible utilization of freeze separation 526 techniques in wastewater purification. Freeze purification could be seen more as an alternative 527 method to be used in conjunction with conventional treatment in purification of a very specific 528 wastewater fraction or when reduction of the volume of wastewater is needed. Due to the 529 (theoretically) non-selective nature of ice crystallization as regards the rejection of impurities, 530 further research is still required on separation of specific fractions like microplastics and fibers.

\section{4. Conclusions}

532 In the present study, the ice growth rates and purification efficiencies of urban wastewaters 533 subject to various freezing conditions (different temperature and air flow velocity) were 534 determined. The research approach used enabled simple evaluation of the purity and mass 535 production rate of ice in freeze purification of wastewaters. The ice growth rate was found to be 536 clearly temperature-dependent, but air flow velocity also had a significant direct effect on ice 
537 growth. Temperature change of $+1^{\circ} \mathrm{C}$ caused the ice mass growth rate to increase by $300 \mathrm{~g} \mathrm{~h}^{-}$

$538{ }^{1} \mathrm{~m}^{-2} .1 \mathrm{~ms}^{-1}$ increase in air flow velocity (at the same temperature) caused the ice mass growth

539 rate to increase by $230 \mathrm{~g} \mathrm{~h}^{-1} \mathrm{~m}^{-2}$. The influence of wastewater concentration on ice growth was

540 found to be minor compared to the effect of temperature and air flow.

541 The hypothesis of the inverse effect of increased ice growth rate on water purification was shown

542 to be valid also with wastewaters (as studied previously with salt solutions): higher purification

543 efficiencies were obtained with lower ice growth rates. The highest purification efficiencies $>95 \%$

544 (COD concentrations in ice $<10 \mathrm{mg} \mathrm{L}^{-1}$ ) were obtained with pretreated municipal wastewater and

545 ice mass growth rate of $<200 \mathrm{~g} \mathrm{~h}^{-1} \mathrm{~m}^{-2}$ (at $\sim-1{ }^{\circ} \mathrm{C}$ and $0.5 \mathrm{~ms}^{-1}$ ). With landfill leachate the highest

546 COD separation efficiency $90 \%\left(\sim 50 \mathrm{mg} \mathrm{L}^{-1}\right)$ was obtained with an ice mass growth rate of $<400$

$547 \mathrm{~g} \mathrm{~h}^{-1} \mathrm{~m}^{-2}$ (at $\sim-1{ }^{\circ} \mathrm{C}$ and $\left.1 \mathrm{~ms}^{-1}\right)$ but the efficiency began to decrease as the growth rate increased.

548 Nevertheless, natural freezing can be considered as a potential treatment method for wastewaters

549 containing significant amounts of organic and inorganic matter. This outcome together with the

550 findings for ice growth provide a good basis for further studies in the area of the freeze purification

551 application design.

552 Acknowledgements

553 The research was funded by the Academy of Finland, project no. 285064. The authors wish to 554 thank Riitta Moisio at Lappeenrannan Lämpövoima Oy and Heidi Oksman-Takalo at Etelä555 Karjalan Jätehuolto Oy for their co-operation and assistance. The contribution of Mr. Maxime 556 Demuyter and Mr. Lucas Goarvot during the experimental work is also acknowledged.

\section{Appendix A. Supplementary data}

558 Supplementary data produced during this research can be found at https://... 
560 Bigger, K.W., Donahue, R., Sego, D. Johnson, M Birch S., 2005. Spray freezing decontamination 561 of tailings water at the Colomac Mine. Cold Regions Science and Technology 42, 106-119. 562 https://doi.org/10.1016/j.coldregions.2004.12.005.

563 Bogdan A., Molina, J., 2017. Physical chemistry of the freezing process of atmospheric aqueous 564 drops. The Journal of Physical Chemistry A 121(16), 3109-3116. 565 https://doi.org/10.1021/acs.jpca.7b02571.

566 Chang, J. Zuo, J. Lu, K-J, Chung T-S, 2016. Freeze desalination of seawater using LNG cold 567 energy. Water Research 102, 282-293. https://doi.org/10.1016/j.watres.2016.06.046.

568 Feng W., Yin, Y., de Lourdes Mendoza M., Wang, L., Chen, P., Liu, Y., Cai, L., Zhang, L., 2018.

569 Oil recovery from waste cutting fluid via the combination of suspension crystallization and freeze570 thaw processes. Journal of Cleaner Production 172, 481-487. 571 https://doi.org/10.1016/j.jclepro.2017.09.281.

572 Gao, W., Habib, M., Smith, D.W., 2009. Removal of organic contaminants and toxicity from 573 industrial effluents using freezing process. Desalination 245, 108-119. 574 https://doi.org/10.1016/j.desal.2008.06.013.

575 Gao, W., Shao, Y., 2009. Freeze concentration for removal of pharmaceutically active compounds 576 in water. Desalination 249, 398-402. https://doi.org/10.1016/j.desal.2008.12.065.

577 Gao, W., Smith, D.W., Sego, D.C., 1999. Ice nucleation in industrial wastewater. Cold Regions 578 Science and Technology 29, 121-133. https://doi.org/10.1016/S0165-232X(99)00019-1.

579 Gao, W., Smith, D.W., Sego, D.C., 2004. Treatment of pulp mill and oil sands industrial 580 wastewaters by the partial spray freezing process. Water Research 38, 579-584. 581 https://doi.org/10.1016/j.watres.2003.10.053 
582 Greenberg, A.E., Franson, M.A. H., Eaton, A.D., Clesceri, L. S., 1995. Standard methods for the 583 examination of water and wastewater. 19th ed. Washington (DC): American Public Health 584 Association.

585 Hasan, M., Filimonov, R., John, M., Sorvari, J., Louhi-Kultanen, M., 2018. Influence and CFD 586 analysis of cooling air velocity on the purification of aqueous nickel sulfate solutions by freezing. 587 AIChE Journal 64, 200-208. https://doi.org/10.1002/aic.15885.

588 Hasan, M., Louhi-Kultanen, M., 2015. Ice growth kinetics modeling of air-cooled layer 589 crystallization from sodium sulfate solutions. Chemical Engineering Science 133, 44-53. 590 https://doi.org/10.1016/j.ces.2015.01.050.

591 Hasan, M., Louhi-Kultanen, M., 2016. Water purification of aqueous nickel sulfate solutions by air 592 cooled natural freezing. Chemical Engineering Journal 294, 176-184. 593 https://doi.org/10.1016/j.cej.2016.02.114.

594 Hasan, M., Rotich, N., John, M., Louhi-Kultanen, M., 2017. Salt recovery from wastewater by air595 cooled eutectic freeze crystallization. Chemical Engineering Journal 326, 192-200. 596 https://doi.org/10.1016/j.cej.2017.05.136.

597 John, M., Suominen, M., Sormunen, O-V., Hasan, M., Kurvinen, E., Kujala, P., Mikkola, A., Louhi598 Kultanen, M., 2018. Purity and mechanical strength of naturally frozen ice in wastewater basins. 599 Water Research 145, 418-428. https://doi.org/10.1016/j.watres.2018.08.063.

600 Lorain, O., Thiebaud, P., Badorc, E., Aurelle, Y., 2001. Potential of freezing in wastewater 601 treatment: Soluble pollutant applications. Water Research 35(2), 541-547. 602 https://doi.org/10.1016/S0043-1354(00)00287-6.

603 Mullin, J. W., 2001. Crystallization. 4th ed. Oxford: Butterworth-Heinemann. 
604 Prasse, G., Stalter, D., Schulte-Oehlmann, U., Oehlmann, J., Ternes, T. A., 2015. Spoilt for 605 choice: A critical review on the chemical and biological assessment of current wastewater 606 treatment technologies. Water Research 87, 237-270. 607 https://doi.org/10.1016/j.watres.2015.09.023.

608 Randall, D.G., Nathoo, J., 2015. A succinct review of the treatment of Reverse Osmosis brines 609 using Freeze Crystallization. Journal of Water Process Engineering 8, 186-194. 610 https://doi.org/10.1016/j.jwpe.2015.10.005.

611 Randall, D.G., Zinn, C., Lewis A. E., 2014. Treatment of textile wastewaters using Eutectic Freeze 612 Crystallization. Water Science \& Technology 70(4), 736-741. 613 https://doi.org/10.2166/wst.2014.289.

614 Rodriguez-Narvaez, O.M., Peralta-Hernandez, J.M., Goonetilleke, A., Bandala, E.R., 2017. 615 Treatment technologies for emerging contaminants in water: A review. Chemical Engineering 616 Journal 323, 361-380. https://doi.org/10.1016/j.cej.2017.04.106.

617 Shirai, Y., Wakisaka, M., Miyawaki, O., Sakashita, S., 1998. Conditions of producing an ice layer 618 with high purity for freeze wastewater treatment. Journal of Food Engineering 38(3), 297-308. 619 https://doi.org/10.1016/S0260-8774(98)00115-0

620 Tchobanoglous G., Burton F.L., Stensel D.H., 2003. Wastewater engineering: Treatment and 621 reuse. 4. ed. McGraw-Hill, New York.

622 van der Ham, F., Seckler, M. M., Witkamp, G. J., 2004. Eutectic freeze crystallization in a new 623 apparatus: the cooled disk column crystallizer. Chemical Engineering and Processing: Process 624 Intensification 43(2), 161-167. https://doi.org/10.1016/S0255-2701(03)00018-7. 
625 Williams, P.M., Ahmad M., Connolly, B.S., Oatley-Radcliffe, D.L., 2015. Technology for freeze 626 concentration in the desalination industry. Desalination 356, 314-327. 627 https://doi.org/10.1016/j.desal.2014.10.023.

628 Yin, Y., Yang, Y., de Lourdes Mendoza, M., Zhai, S., Feng W.L., Wang, Y., Gu, M., Cai, L., Zhang, 629 L., 2017. Progressive freezing and suspension crystallization methods for tetrahydrofuran 630 recovery from Grignard reagent wastewater. Journal of Cleaner Production 144, 180-186. 631 https://doi.org/10.1016/j.jclepro.2017.01.012. 